\title{
DESAFIOS DO ENSINO DA LITERATURA POR MEIO DE MÉTODOS MULTIMODAIS'
}

\section{CHALLENGES OF TEACHING LITERATURE THROUGH MULTIMODAL METHODS}

\author{
Gilmei Francisco Fleck² \\ Michele de Fátima Sant'Ana ${ }^{3}$ \\ Cristian Javier Lopez ${ }^{4}$
}

RESUMO: Refletimos aqui sobre os desafios enfrentados no ensino de leitura do texto literário no Ensino Fundamental I e como podemos alcançar melhores resultados por meio da utilização de textos multimodais para despertar o interesse para as leituras e atividades literárias no Ensino Fundamental, aguçando a curiosidade, o desejo de investigação e a criatividade dos alunos. Isso para levá-los a repensar o que já sabem e agregar novos conhecimentos àqueles já vivenciados por meio do estabelecimento de relações intertextuais e a integração de conhecimentos culturais. Nossa proposta se concretiza em forma de "Oficinas literárias temáticas", ancoradas nos pressupostos de Jauss (1979), Mendoza Fillola (1994) e na conjugação destes, numa metodologia de abordagem que valoriza os textos multimodais. PALAVRAS-CHAVE: Leitura. Texto Literário. Formação do Leitor Literário. Textos multimodais. Profletras.

ABSTRACT: We reflect here on the challenges faced in teaching literary texts reading in Elementary School I and how we can achieve better results through the use of multimodal texts as means of arising the interest of students in the initial stage of training for the readings and activities presented to them, sharpening their curiosity, their desire for investigation and creativity. This is to make them rethink what they already know and add new knowledge to those already experienced through the establishment of intertextual relations and the integration of cultural knowledge. Our proposal is materialized in the form of "Thematic Literary Workshops", anchored on the assumptions of Jauss (1979), Mendoza Fillola (1994) and their combination, through a methodology which valorizes multimodal texts.

KEYWORDS: Reading. Literary text. Formation of Literary Reader. Multimodal texts. Profletras.

\footnotetext{
${ }^{1}$ Artigo recebido em 15/04/2020 e aceito para publicação em 15/06/2020.

2 Pós-doutor em Literatura Comparada e Tradução pela Uvigo/Espanha. Doutor em Letras pela UNESP/Assis. Professor associado da UNIOESTE/PR. ORCID: https://orcid.org/0000-0002-4228-2566. E-mail: chicofleck@yahoo.com.br.

${ }^{3}$ Doutoranda em Letras da UNIOESTE/PR. Mestre (PROFLETRAS) pela UNIOESTE/PR. Professora na Secretaria Municipal de Educação de Santa Tereza do Oeste/PR. ORCID: https://orcid.org/00000003-1422-9503. E-mail: michelefsantana@hotmail.com.

${ }^{4}$ Doutor em Estudos Literários pela Uvigo/Espanha em cotutela com a UNIOESTE/Brasil. Mestre em Teatro e Artes Cênicas/Estudos Literários, pela Uvigo/Espanha. ORCID: https://orcid.org/00000002-7391-8395. E-mail: cj_lopez2@hotmail.com.
}

Interdisciplinar, Sằo Cristóvăo, UFS, v. 33, jan-jun, p. 101-117, 2020 D0I: https://doi.org/10.47250/intrell.v33i1.14180 


\section{Introduçầo}

Falar de leitura, de formação do leitor, sobre o ensino de leitura do texto literário no Ensino Fundamental e os desafios enfrentados cotidianamente pelos profissionais da educação não é algo muito difícil, haja vista nossa realidade educacional atual. Contudo, quando essa expressão toma a forma de reflexão, outras necessidades surgem, como, por exemplo, uma base teórica que sustente essa ação educacional e ampare as metodologias empregadas para que se alcancem resultados efetivos.

Nosso desafio aqui é, pois, refletir sobre como podemos alcançar melhores resultados nesse contexto da formação de um leitor infantil, por meio da utilização de métodos e estratégias que se voltem aos textos multimodais como objetos de leitura que contribuem para instigar o interesse do educando para as leituras sugeridas e para a realização das atividades a eles apresentadas. Isso tudo para despertar-lhes a curiosidade, para a ampliação de seus horizontes, conforme defende Jauss (1979), ao relacionarem um texto escrito a uma pintura, a um filme, a uma música, segundo expressa Mendoza Fillola (1994); o desejo de investigação, que Ihes permite conectar os temas e as matérias discutidas em sala de aula àqueles aspectos de seus interesses cotidianos, via buscas e consultas nos tantos sites disponíveis para isso; e a criatividade, para estabelecer relações intertextuais entre as diferentes mídias nas quais os textos da temática discutida podem ser apresentados e repensar o que já sabem a esse respeito. Isso para que, a esses conhecimentos já incorporados, possam integrar novos, por meio de trocas e interações com os colegas de sala, com familiares, membros da comunidade, numa efetiva integração de conhecimentos culturais, de acordo com a proposta de intervenção de Zucki (2015, p. 55) que, ao referir-se à escolarização da literatura, comenta:

[...] compreendemos que essa escolarização da literatura só pode ser adequada se pensada e sistematizada a partir de fundamentos criteriosos, ou seja, baseada em uma teoria que sustente, tanto seus objetivos e perspectivas, quanto suas ações metodológicas.[...]. Tal prática de leitura está organizada segundo os princípios da Estética da Recepção e da Literatura Comparada. Em nossa proposta de leitura, a inclusão 
da intertextualidade literária ligadas às produções artísticas de outras áreas (como a pintura, a música, o desenho, etc.) possibilita ao leitor explorar os diálogos culturais e a beleza estética como premissas para uma aprendizagem crítica.

Essas trocas também podem ser efetuadas por meio de produções de releituras, dramatizações, expressões artísticas etc., que possam ser compartilhadas no espaço familiar e escolar. Acreditamos que, com um trabalho sério, bem planejado e sob a mediação de um professor comprometido com a formação dos seus educandos, o uso de textos multimodais - amalgamados em uma temática comum -, e a oferta de material simbólico que desperte nos alunos o gosto pela leitura, oportunizarão às crianças, na fase inicial de formação escolar, o progressivo reconhecimento de que a linguagem é material manipulável e que a arte literária, assim como outras artes, utilizam-se de diferentes materiais, vale-se dos signos linguísticos para explorá-los em todo seu potencial representacional, metafórico, conotativo. Tal abordagem aos textos literários vai, gradativamente, construindo um leitor literário consciente, ou seja, aquele leitor que, diante de um conto, uma poesia, uma crônica, uma fábula, um romance, compreende que o texto a sua frente se trata de um objeto artístico, construído pela manipulação da linguagem, constituído pelo emprego consciente de técnicas e estratégias escriturais que privilegiam o uso conotativo da linguagem na transmissão de ideias, concepções e ideologias. Que seu objetivo maior é produzir prazer e que sua leitura deve gerar fruição.

Tal processo - potencializado pela capacidade de estabelecer relações intertextuais, promovida pelas leituras de textos multimodais - requer tempo e investimento por parte dos docentes, mas deve principiar já no Ensino Fundamental I, nas séries iniciais, quando os alunos ainda estão empolgados pela magia frente às possibilidades de representação da fala pela escrita. Nosso texto, portanto, deriva de uma pesquisa interventiva, que possui essa característica de buscar recursos didático-metodológicos - como a proposição de inter-relações culturais do leitor com seu meio social, práticas comparativas entre o texto literário e outras artes, compartilhamento de saberes, exploração do lúdico na literatura, 
entre outros - para tornar o ensino da literatura efetivo e prazeroso desde o início da escolarização. Para isso, propomos "Oficinas literárias temáticas" para amalgamar textos de diferentes naturezas, mas que contemplam uma mesma temática, a fim de oportunizar aos alunos o aprofundamento de uma mesma discussão, por meio de distintas leituras que, entre si, dialogam e ampliam os sentidos. Desse modo, os textos multimodais não direcionam o aprendiz ora para um lado e ora para outro, mas potencializam a sua capacidade de refletir sobre um mesmo tema, tornando-o, lentamente, um leitor consciente.

\section{Ensino da Literatura por meio dos textos multimodais: um universo intertextual}

Refletir sobre a aprendizagem da leitura e sua importância na formação do leitor literário e de como o contato precoce com a literatura e os textos multimodais repercute na qualidade da alfabetização e da formação da criança enquanto indivíduo que, por meio de uma conversa com as páginas lidas e de sua própria imaginação, tem a oportunidade de se reconhecer nas histórias, é o que nos permite dimensionar o sentido profundo e importante da literatura e da leitura em nossas vidas.

Esta expressão é vista como arte humanizadora, segundo expressam Candido (1972) - ao defender a humanização gerada pela leitura do texto literário -; Lajolo (1993, p. 106) - ao comentara que "é à literatura, como linguagem e como instituição, que se confiam os diferentes imaginários, as diferentes sensibilidades, valores e comportamentos através dos quais uma sociedade expressa e discute, simbolicamente, seus impasses, seus desejos, suas utopias" - e Zilberman (2009, p. 35) - quando menciona que "[...], a proposta de que a leitura seja enfatizada na sala de aula significa o resgate de sua função primordial, buscando, sobretudo, a recuperação do contato do aluno com a obra de ficção." Essa arte, para as crianças em formação, ainda no Ensino Fundamental I, volta-se à criatividade, à ludicidade e à imaginação que as fazem transcender de seu universo concreto às experiências leitoras dos espaços mágicos e fantasiosos da literatura infantil e juvenil. Nesse contexto, 
[...] saber que a imaginação nos permite ser outras pessoas e nós mesmos, descobrir que podemos pensar, nomear, sonhar, encontrar, comover e decifrar a nós mesmos nesse grande texto escrito a tantas vozes por uma infinidade de autores ao longo da história, é o que dá sentido à experiência literária como expressão de "nossa humanidade comum". (REYES, 2010, p. 15).

O campo da literatura Infantil e Juvenil, por sua natureza essencialmente lúdica, recreativa, ilustrativa, imagética, está ancorado fortemente na imaginação, não se diferenciando, desse modo, da literatura para adultos, vista, por exemplo, pelo Nobel de Literatura, Mario Vargas Llosa (2000, p. 394), como o espaço imaginário que "[...] nos permite viver em um mundo cujas leis transgredem as leis inflexíveis através da qual passa nossa vida real, emancipados da prisão do espaço e do tempo, na impunidade do excesso e donos de uma soberania que não conhece limites. ${ }^{5 \prime \prime}$ (nossa tradução). Embora o texto literário tenha essa premissa de nos possibilitar "outras experiências" fora de nossas limitações - o que deveria levá-lo a ser apreciado pelos estudantes - a formação de leitores literários não é uma tarefa fácil, e talvez por isto tenha sido negligenciada ao longo de tantos anos, inclusive no espaço escolar. Nesse sentido, cabe lembrar que

[...] o texto literário tem muito a contribuir para o aprimoramento pessoal, para o autoconhecimento, sem falar do constante desvelamento do mundo e da grande possibilidade que a leitura de determinada obra oferece para o descortínio de novos horizontes para o homem, no sentido da formação e do refinamento da personalidade. (SILVEIRA, 2005, p. 16).

Desse modo, ensinar às crianças a lerem por meio do uso de textos multimodais - incluindo-se a vasta produção literária disponível - adquire essa dimensão de "descortínio de novos horizontes" e o "refinamento da personalidade", um processo muito mais amplo do que o ato de decodificar e codificar os signos linguísticos. Para que isso ocorra, faz-se necessário um minucio-

\footnotetext{
${ }^{5}$ Texto original: “[...] nos permite vivir en un mundo cuyas leyes transgreden las leyes inflexibles por las que transcurre nuestra vida real, emancipados de la cárcel del espacio y del tiempo, en la impunidad para el exceso y dueños de una soberanía que no conoce límites."
}

Interdisciplinar, Săo Cristóvăo, UFS, v. 33, jan-jun, p. 101-117, 2020 D0I: https://doi.org/10.47250/intrell.v33i1.14180 
so planejamento de cada atividade elaborada, de como será sua implementação, dos objetivos traçados, dos métodos que serão utilizados e, por fim, uma análise que leve a conclusões sobre o efetivo aprendizado ou com vistas às lacunas que ainda seguem como necessidades no processo. Esse trabalho, que para alguns parece árduo, é sempre muito recompensador, pois

[...] se todos passamos pela infância e se está demonstrado que o que se constrói nesses anos implica qualidade de vida, oportunidades educativas e, por consequência, desenvolvimento individual e social de cada indivíduo, "oferecer leitura" às crianças menores pode contribuir para a construção de um mundo mais equitativo, propiciando a todos as mesmas oportunidades de acesso ao conhecimento e à expressividade desde o começo da vida. (REYES, 2010, p. 16).

Nossa sociedade, especialmente os órgãos reguladores, por meio de documentos e diretrizes, BNCC (2017), DCEs (2008), esperam da escola, ao menos a nível discursivo, a formação de um "leitor crítico", capaz de transitar por diferentes modalidades textuais e interpretá-las com desenvoltura e aproveitamento. Contudo, não mencionam que o contexto no qual esse sujeito deve se formar é o de uma sociedade que, por séculos, foi colonizada, sendo que, nesse processo, uma minoria teve acesso às ferramentas de ler e escrever, enquanto uma grande massa foi escravizada, explorada e subjugada. Entre esses processos de subjugação, esteve sempre presente o impedimento às mulheres, indígenas e africanos/afrodescendentes ao acesso à escola e, consequentemente, ao aprendizado da leitura e da escrita. Na atualidade, ao seguir as diretrizes que regulam o ensino Fundamental e Médio, encontramos todos os indicativos de como proceder, como se a base para isso estivesse solidamente construída. Parece não haver um entendimento claro de que

[...] este processo tem seu início nos primeiros anos de vida, nos contatos iniciais da criança com o mundo mágico, fantástico e aberto da literatura infantil, cujo acesso garante o aprimoramento do processo de aprendizagem da linguagem como meio de construção e representação da realidade. (FLECK, 2017, p. 26).

Interdisciplinar, Săo Cristóvăo, UFS, v. 33, jan-jun, p. 101-117, 2020 D0l: https://doi.org/10.47250/intrell.v33i1.14180 
Nas propostas de ensino que privilegiam a leitura de textos multimodais no Ensino Fundamental jamais se deveria descartar os gêneros literários. É comum que professores desta fase fundamental de ensino, pela sua formação acadêmica na área de educação, mais voltada à alfabetização, careçam de conhecimentos teóricos - e de experiências de leitura mesmo - sobre textos literários e as distintas possibilidades de abordagem a esses textos que, por sua natureza artística, polissêmica, deve ser diferenciada de outros gêneros textuais. Assim, devemos, antes de tudo, conceber que

[...] a riqueza polissêmica da literatura é um campo de plena liberdade para o leitor, o que não ocorre em outros textos. Daí provém o próprio prazer da leitura, uma vez que ela mobiliza mais intensa e inteiramente a consciência do leitor; sem obrigá-lo a manter-se nas amarras do cotidiano. Paradoxalmente, por apresentar um mundo esquemático e pouco determinado, a obra literária acaba por fornecer ao leitor um universo muito mais carregado de informações, porque o leva a participar ativamente da construção dessas, com isso forçando-o a reexaminar a sua própria visão da realidade concreta. (BORDINI, AGUIAR, 1988, p. 15).

Essa "riqueza polissêmica da literatura" é inerente a essa arte e integra o conjunto da Literatura, sem adjetivos e sem restrições à idade ou etapas formativas. Do mesmo modo, a relação entre ficção e realidade é promovida no próprio processo de humanização que esta arte promove, pois "em todo processo de educação da criança, a formação da imaginação não tem apenas um significado particular do exercício e do desenvolvimento de alguma função separada, mas um significado geral que se reflete em todo o comportamento humano." (VIGOTSKI, 2009, p. 59).

Ao priorizarmos a fruição na leitura do texto literário, e não uma série de respostas assertivas e, na maioria das vezes, fechadas em si mesmo, como resposta por parte dos alunos, deixamos nossa posição de "conhecedores da situação de ensino" e assumimos uma postura de "compartilhamento" de saberes e trocas de conhecimentos culturais. No texto literário infantil, normalmente, temos, também, o apoio de imagens e outros recursos visuais que potencializam os enunciados e expandem a dimensão comunicativa da linguagem verbal. Se esses textos forem utilizados como guia

Interdisciplinar, Sầo Cristóvăo, UFS, v. 33, jan-jun, p. 101-117, 2020 D0I: https://doi.org/10.47250/intrell.v33i1.14180 
para outras possíveis leituras multimodais, a essência polissêmica do texto literário torna-se ainda mais significativa, pois expande sua ação a outros objetos, situações e mídias. Nesse sentido, a obra Reading Images: The Grammar of Visual Design, dos autores Kress e Van Leeuwen (1996), é um apoio muito importante para os estudos sobre multimodalidade. Nela, encontramos uma sistematização da abordagem da linguagem visual, tomando como base vários exemplos de textos, cujas abordagens apresentadas podem ser aplicadas aos objetos/textos multimodais lidos em sala de aula. Quando tais objetos/textos forem organizados dentro de uma temática única, com uma certa abrangência temporal de atividades direcionadas ao aprofundamento de posições e expressões sobre essa temática, estaremos no caminho da construção daquilo que, aqui, já definimos como um leitor literário consciente.

De acordo com Kress (2000), para adotar a teoria multimodal, faz-se necessário pensar nestes três dados: o primeiro deles mostra que "todos os textos são multimodais" (2000, p. 187), isso faz com que qualquer tipo de texto, verbal ou não, seja considerado multimodal e, dessa forma, qualquer texto pode ser analisado sob o enfoque multimodal. O segundo dado afirma que, apesar de todos os textos serem multimodais, alguns destes possuem um modo predominante. Assim, um modo pode ter sua função destacada em relação a outros num mesmo texto, mas isto não desfavorece os outros, sendo todos, portanto, passíveis de análise. O terceiro dado consiste na afirmação de que todos os sistemas de comunicação e representação são multimodais. Ou seja, se todos os textos são multimodais, isto significa que a forma como foram estruturados também é multimodal. Dessa maneira, podemos afirmar que, num texto verbal, por exemplo, a sua divisão em tópicos, a cor da fonte, a subordinação de itens e, até mesmo, os espaços presentes têm funções significativas.

A eleição de uma temática geral - "Eu e a natureza: muitas relações", abordada em subtemáticas em cada Módulo planejado -, é o fator que nos possibilitou organizar uma série de leituras multimodais, concentradas ao redor de uma única proposta de discussão para o aprofundamento dos posicionamentos e expressões dos alunos sobre ela. Assim, à continuação, expomos alguns aspectos relevantes desta nossa experiência de intervenção didático-pedagógica no Ensino Fundamental I. 


\section{Uma experiência de leituras multimodais em "Oficinas literárias temáticas"}

Com o objetivo de implementar uma proposta de trabalho com textos multimodais, optamos pelo modelo didático apresentado por Mendoza Fillola (1994, p. 91), em que o autor fundamenta-se nas teorias que sustentam que a leitura e sua aprendizagem devem respeitar a colaboração do leitor e seu interesse como fontes de incentivo para a aquisição do hábito e do gosto pela leitura. Este modelo didático é aplicado em fases que pressupõem o estudo, que direciona o processo de trabalho e os objetivos a serem alcançados com os alunos e sugere um conjunto de atividades criado pelo autor, com objetivos traçados, passando pela coleta e sistematização de dados, pela metacognição do processo e habilidades de leitura de cada educando e, finalizado com as conclusões por meio da análise dos dados coletados. Essas fases dividem-se em etapas que devem ser consideradas no estudo comparativo como a aproximação de conceitos chaves, a sistematização da metodologia da literatura comparada, o estudo integrado de diferentes obras literárias em interação com outras artes e textos e a integração dos conhecimentos culturais. Assim, nosso objetivo centraliza-se em propor um modo interativo de trabalho com o texto literário e os textos multimodais, estabelecidos por meio da apresentação de outras formas de arte como a música, a pintura, o cinema, entre outros, como meio de instigar reflexões nos educandos sobre a intertextualidade e a continuidade que as obras literárias mantêm com as nossas vidas e com as nossas relações cotidianas e sociais.

Dessa forma, para planejar nosso projeto de intervenção, procuramos seguir as estratégias pautadas no método comparatista, metodologicamente, pela recepção leitora, pelas conexões intertextuais e pelas estratégias cognitivas, por acreditarmos que, assim, seja possível aproximar a leitura dos leitores em formação e lhes oportunizar a criação do gosto e do hábito pela mesma. Assim, buscamos, por meio de uma prática aplicada com "Oficinas literárias temáticas", superar as dificuldades encontradas com o trabalho de letramento literário nos anos escolares iniciais e tornar essa caminhada formativa possivel já desde as primeiras experiências. Assim, nossas "Oficinas literárias temáticas" aconteceram, 
basicamente, priorizando as seguintes etapas: 1 - Apresentação das obras e determinação do horizonte de expectativas; 2 - Recepção e análise das obras; 3- Integração de conhecimentos culturais e 4- Conclusões. Tais procedimentos de abordagem à leitura em "Oficinas literárias temáticas" foram elaboradas por Zucki (2015, p. 66) que, como nós, ancorou-se, para isso, nos pressupostos da Estética da Recepção e nas proposições de Mendoza Fillola (1994).

As "Oficinas literárias temáticas" e as ações de leitura foram planejadas com base em uma temática geradora que propiciasse as discussões que levassem à conexão da ficção com a realidade. Quando consideramos que estas práticas serão efetuadas com alunos de um 3 o ano do Ensino Fundamental, vimos a possibilidade de reunir uma série de textos - em diferentes gêneros e dispositivos - em torno do tema "Eu e a natureza: muitas relações". Isso porque acreditamos que esta temática pudesse despertar nestes alunos um envolvimento que trouxesse conscientização, ações responsivas e atitudes responsáveis, como de fato se verificou ao longo do andamento do projeto. Justificamos essa temática pelo fato citado e, também, porque vemos cotidianamente como, nesta fase do desenvolvimento, as crianças são sensíveis aos animais, às plantas, aos problemas ecológicos - aludidos, representados, personificados na seleção de textos literários e de outras artes que efetuamos - e a tantos outros assuntos que esta temática pode congregar e cujas discussões resultam em um sujeito mais consciente e responsável no e pelo entorno no qual sua vida transcorre. Desse modo, também a intenção de aprimorarmos com eles alguns aspectos voltados ao nível sensorial e emocional de leitura pode resultar eficaz quando inseridos e contextualizados por uma temática que lhes seja importante.

Para isso, organizamos a proposta de aplicação de nossas "Oficinas literárias temáticas" em seis módulos, contando ainda com a Diagnose inicial e o Encerramento das oficinas, seguindo, sempre, a sistematização já elaborada por Zucki (2015). A partir de obras voltadas à representação da natureza na literatura e em outras artes, selecionamos um subtema para organizar as atividades de cada Módulo e, por fim, procedemos à seleção de outras formas de arte, como obras de arte plástica, músicas e mídias que fizessem possível a tessitura da comparatística, proposta por Mendoza Fillola (1994), a partir da realidade do leitor em forma-

Interdisciplinar, Săo Cristóvăo, UFS, v. 33, jan-jun, p. 101-117, 2020 D0I: https://doi.org/10.47250/intrell.v33i1.14180 
ção. Para desenvolvermos a atividade interventiva, dividimos as aulas em seis módulos, constando, também, a diagnose inicial e o encerramento das oficinas, conforme demonstramos no quadro das ações abaixo estabelecido:

TEMÁTICA GERADORA: "Eu e a natureza: muitas relações"

DIAGNOSE INICIAL: passeio pelo espaço escolar.

MóDULO 1 (duração de 5 aulas)

Subtema da prática: As árvores e seus frutos: dádivas da natureza

MÓdULO 2 (duração de 5 aulas)

Subtema da prática: Relações do ser humano com as flores

MóDULO 3 (duração de 5 aulas)

Subtema da prática: O pequeno e organizado universo dos insetos e seus grandes efeitos

MÓDULO 4 (duração de 5 aulas)

Subtema da prática: A água: fonte de vida na terra

MódULO 5 (duração de 5 aulas)

Subtema da prática: Os animais precisam de carinho e de respeito

MódULO 6 (duração de 5 aulas)

Subtema da prática: Das sensações de Margarida aos cuidados com a vida ENCERRAMENTO DAS OFICINAS: novo passeio, novos olhares.

Fonte: elaborado pelos autores para as Oficinas Literárias temáticas (2019).

Desse conjunto de oficinas que integram a temática geral "Eu e a natureza: muitas relações", na sequência, dedicamo-nos a explicitar os procedimentos realizados ao longo do Módulo I, para exemplificar nossos procedimentos didáticos metodológicos ancorados na experiência prévia de Zucki (2015).

Oficinas literárias temáticas: "Eu e a natureza: muitas relaçồes": Módulo I - "As árvores e seus frutos: dádivas da natureza"

Iniciamos nossas oficinas com a atividade diagnóstica, convidando os alunos para um passeio pela escola. Nossa intenção aqui era, após o passeio, pedirmos que os mesmos fizessem um desenho, retratando o que viram durante o percurso em forma de representação artística, para que nós, enquanto pesquisadores, tivéssemos uma visão primária do que eles tinham já interiorizado

Interdisciplinar, Sằ Cristóvầo, UFS, v. 33, jan-jun, p. 101-117, 2020 D0I: https://doi.org/10.47250/intrell.v33i1.14180 
da temática e das subtemáticas que estávamos propondo para o desenvolvimento de nosso projeto e, assim também, termos, ao final, a confirmação ou não de nossas hipóteses. Feito o diagnóstico inicial, demos início ao Módulo I de nossa intervenção, conforme segue descrito à continuação.

Subtema da prática do módulo I: "As árvores e seus frutos: dádivas da natureza" ${ }^{1}$, vista por meio das obras Árvore generosa ${ }^{7}$ (2012), de Shel Silverstein; Árvore ${ }^{8}$ (2013), de João Proteti, Folha ${ }^{9}$ (2008), de Stephen Michael King, o episódio "Dádiva da vida", da animação "Ursinhos carinhosos"10 e as pinturas "Maçã"11, de Salvador Dalli e "Maçã"12 de Romero Britto.

Como sugestão para o Módulo I, selecionamos obras que apresentam diferentes "árvores e seus frutos" por ser algo bem próximo da realidade de nossos alunos, pois, todos eles têm contato com diversas árvores e frutas em seus quintais e no entorno da escola e da cidade onde vivem. Também são histórias que possibilitam a aquisição de conhecimentos sobre leitura e literatura de maneira lúdica e prazerosa, pois, os mesmos estabelecem relação com as árvores nas quais costumam brincar não só em seus lares, como também no pátio da escola na hora do recreio.

Apresentação das obras e determinação do horizonte de expectativas: Na primeira etapa do módulo, sugerimos que a sala seja preparada com as carteiras dispostas em semicírculo e os alunos dispostos livremente, com projetor de multimídia, com ilustrações sobre o tema nas paredes e materiais que poderão ser utilizados pelos alunos como cartolinas, papéis sulfite, canetinhas, lápis de cor, tesourinha, entre outros. O subtema deverá ser exposto em painel ou cartaz. Após informados sobre o subtema e instalados adequadamente para o início das atividades, o professor pode

\footnotetext{
${ }^{6}$ Como este texto está voltado a uma exemplificação de como trabalhar com "oficinas literárias temáticas" - cujo corpus de leitura abrange textos de diferentes naturezas - e pela sua extensão bastante reduzida, limitamo-nos, aqui, a apenas citar as obras do Módulo em destaque, porém sugerimos a sua leitura na íntegra por aqueles leitores cujo interesse esteja no Ensino-aprendizagem de Literatura infantil.

7 SILVERSTEIN, S. A árvore generosa. Tradução de Fernando Sabino. 13. ed. São Paulo: Cosac Naify, 2012.

8 PROTETI, J. Árvore. São Paulo: Edições MMM, 2013.

${ }^{9}$ KING, S. M. Folha. Traduzido por Gilda de Aquino. São Paulo: Brinque-Book, 2008.

${ }^{10}$ Disponível em https://www.youtube.com/watch?v=mLnWmReS4Z8. Acesso em: 03 mai. 2019.

${ }^{11}$ Disponível em https://nl.pinterest.com/pin/538602436679531735/?lp=true. Acesso em: 21 mai. 2019.

${ }^{12}$ Disponível em https://br.pinterest.com/pin/476748310532782201/?lp=true. Acesso em: 21 mai. 2019.
}

Interdisciplinar, Săo Cristóvăo, UFS, v. 33, jan-jun, p. 101-117, 2020 D0I: https://doi.org/10.47250/intrell.v33i1.14180 
propor uma roda de conversa sobre quais obras e autores serão explorados neste módulo, para identificar o que os alunos sabem (ou não) e pensam sobre eles: quem são (foram), que temas estão sendo abordados, como produziram suas obras, etc., e propiciar- Ihes os primeiros contatos com o material concreto do Módulo. Dessa forma, estabeleceremos o horizonte de expectativas do leitor que será, no decorrer das leituras e atividades realizadas, confirmado ou redimensionado.

Recepção e análise das obras: A primeira sugestão é mostrar aos alunos a capa do livro A Árvore Generosa e perguntar-lhes sobre o que eles pensam que será a história e sobre o que ela vai tratar, considerando apenas o título. Em seguida, o professor deve entregar aos alunos um folder com a imagem inicial e a imagem final do livro A Árvore Generosa, do autor Shel Silverstein, e pedir-lhes que digam o que eles pensam que possa ter acontecido na história ao observarem as figuras, deixando-os livres para expor suas ideias e dialogarem entre si e, então, contar a história da "Árvore Generosa" para os alunos e verificar se algumas das hipóteses se confirmaram.

Em seguida, propor aos alunos a prática de leitura do livro Árvore (2013), de João Proteti. Essa prática pode se adaptar à realidade da turma: leitura silenciosa, leitura oral, leitura jogralizada etc. Feita a leitura, deixar que cada aluno desenhe a sua árvore e a decore. Esses desenhos devem, depois, ser expostos na sala de aula.

Como forma de estimular a visão e a capacidade imaginativa e narrativa, a professora apresentará aos alunos o livro Folha (2008), de Stephen Michael King, que é totalmente ilustrado e construído somente por meio imagético. Isso será feito para que os alunos notem que um texto pode ser lido através de suas imagens e que não é necessário e obrigatório que haja palavras para transmitir ou narrar o que se deseja, pois, as imagens podem e fazem isso também. Voluntários da turma poderão relatar a sua versão da história ilustrada.

Após a leitura, passar o vídeo com a contação da história do livro Folha (2008), feita por Fafá conta histórias ${ }^{13}$, momento em que os alunos poderão assistir a uma versão da história que eles também imaginaram e confirmar suas hipóteses. Em seguida,

${ }^{13}$ Disponivel em https://www.youtube.com/watch?v=kW4TNL9mwYk. Acesso em: 16 jun. 2019. 
dialogar com os alunos e perguntar sobre as árvores que eles conhecem, como elas se chamam, e se, assim como o menino da história, eles também têm uma "árvore amiga" com a qual eles brincam, comem seus frutos etc.

Passar o episódio "A dádiva perdida"14, de "Os Ursinhos Carinhosos" e conversar com os alunos sobre as questões humanizadoras e os valores que norteiam a história assistida como: plantar, colher, cultivar, repartir, cuidar bem da natureza etc.

Apresentar para os alunos as obras de arte: "Maçã", de Salvador Dalli e de Romero Britto, e questionar sobre suas impressões a respeito das telas. Explorar, neste momento, todas as percepções visuais dos alunos e dar-lhes espaço para que manifestem as suas preferências. Em seguida, recortar o formato de uma maçã, em papel colorido, e nele deixar os alunos anotarem algum pensamento com relação aos textos lidos. Fazer um móbile com todas as maçãs recortadas e expor na sala. Se possível, oferecer-lhes maçãs para comerem durante o lanche.

A professora, ao final das atividades deste módulo, presenteará os alunos com uma pequena caderneta "frutal", confeccionada em forma de maçã, para que, nela, os alunos comecem a anotar as suas impressões, sensações, emoções e ideias sobre o projeto de leitura das "Oficinas literárias temáticas". Essa será uma das formas de coleta de dados, necessários à avaliação final do projeto.

Integração de conhecimentos culturais: Nesse momento, de preferência com os alunos dispostos livremente para uma roda de conversa, questionar se eles conhecem alguma outra história que também tenha frutas, ou especificamente a maçã, em seu enredo para desenvolver neles a capacidade de estabelecer relações intertextuais. Instigá-los a relatar histórias que, por ventura, possam conhecer, como é o caso de "Branca de Neve", a "Raposa e as uvas", entre outras e também sobre suas frutas preferidas, seus gostos, etc., e se eles conhecem as árvores que as produzem, os cuidados que com elas se deve ter. Nesse momento, pode-se sugerir que as crianças, em casa, conversem com os seus pais sobre as fruteiras que eles têm, ou que eles conheçam o modo como é o cuidado destas plantas para relatarem isso no encontro seguinte.

${ }_{14}$ Disponível em https://www.youtube.com/watch?v=mLnWmReS4Z8. Acesso em: 03 mai. 2019. 
Conclusões: Por meio do diálogo coletivo, verificar se os alunos compreenderam a importância do cuidado que devemos ter com o meio ambiente e a importância da preservação; conversar sobre a experiência de leitura de diferentes textos referentes a uma mesma temática e questionar os alunos se isso lhes pareceu interessante e por quê. $E$, finalmente, para verificarmos se os alunos estão constituindo conhecimentos a respeito das leituras e análises das obras, sugerimos que o docente analise as ilustrações da caderneta, os relatos orais, os argumentos apresentados pelos alunos e/ou registros escritos, considerando o ano escolar em que se encontram.

Os demais módulos seguem esta mesma estrutura e os passos de abordagem aos textos, integrando o literário ao artístico e estes ao universo cotidiano dos alunos.

\section{Comentários finais}

Ao vermos os resultados positivos da aplicação de nosso projeto, consideramos o método comparativo de Mendoza Fillola (1994), aliado às premissas da Estética da Recepção de Jauss (1979), amalgamados por Zucki (2015) num conjunto de procedimentos de abordagem aos textos multimodais, eficiente como uma alternativa consistente para o trabalho escolar com a literatura, especialmente nas séries iniciais do Ensino Fundamental, pois, nesta fase, é nítido o gosto das crianças pelas atividades artísticas, especialmente as literárias. Os integrantes das oficinas, pelos seus relatos compartilhados com familiares e colegas de outras turmas na escola, desenvolveram, apesar do tempo relativamente curto de execução do projeto, atitudes mais conscientes e responsivas com relação a vários aspectos abordados pela temática "Eu e a natureza, muitas relações", demostradas nas atividades realizadas e nas ações dentro da escola.

A leitura dos textos literários, associada à leitura de diferentes signos artísticos e textos multimodais, serviu não apenas como material lúdico e de expansão dos horizontes de leitura, mas, principalmente, como um recurso cognitivo que auxiliou os alunos a levantarem hipóteses e se interessarem por descobrir se essas hipóteses seriam confirmadas ou não, ao longo do trabalho, com os textos e na troca de experiências e histórias de leitura que, de fato, ocorreram nas oficinas. 
Com base nos resultados das intervenções, enfatizamos que a formação literária, o gosto pela leitura e o uso de textos multimodais como ferramentas de suporte precisa subsidiar a prática pedagógica dos professores, de forma que esta possa contribuir para a formação de alunos leitores de literatura e que a proposta comparatista de Mendoza Fillola (1994), associada às etapas de abordagem ao corpus proposto por Zucki (2015), constitui-se em uma alternativa didática viável, que possibilita ao aluno compreender a literatura constituinte de sua vida como fenômeno cultural, histórico e social.

Destacamos, também, que a leitura de textos multimodais precisa ser organizada para que crianças pequenas possam, de um modo prático e significativo, estabelecer relações entre eles, pela ressignificação de certas expressões artísticas - desenhos, pinturas, dramatizações, releituras imagéticas - como, de fato, sua existência na sociedade se efetiva. Nesse contexto, nossa escolha por "Oficinas literárias temáticas" mostrou-se uma excelente opção porque, além de dar sentido à multiplicidade de textos, também permitem o aprofundamento de pensamentos, posições e opiniões sobre a temática discutida, gerando, com o passar do tempo, aquilo que consideramos o leitor literário consciente.

\section{Referências}

BRASIL. Base Nacional Comum Curricular (BNCC). Educação é a Base. Brasília, MEC/CONSED/UNDIME, 2017. Disponível em: <568 http://basenacionalcomum.mec.gov.br/images/BNCC_publicacao.pdf>. Acesso em: 23 abr. 2020.

BORDINI, M. G.; AGUIAR, V. T. Literatura: a formação do leitor: alternativas metodológicas. Porto Alegre: Mercado Aberto, 1988.

CANDIDO, A. A literatura e a formação do homem. Ciência e Cultura. São Paulo, v. 24, n. 9, p. 803-809, 1972.

FLECK, G. F. Formação do leitor: um projeto socioeducacional - uma trajetória para a vida cidadã. In: FLECK, G. F. (Org.) Literatura Infantojuvenil: desafios para o letramento literário - pesquisas e experiências no âmbito escolar. Curitiba: CRV, 2017, p. 23-37.

JAUSS, H. R. Estética da recepção: colocações gerais. In: LIMA, Luiz Costa (trad. e org.). A literatura e o leitor - textos de estética da recepção. Rio de Janeiro: Paz e Terra, 1979, p. 43-61.

Interdisciplinar, Săo Cristóvăo, UFS, v. 33, jan-jun, p. 101-117, 2020 D0l: https://doi.org/10.47250/intrell.v33i1.14180 
KING, S. M. Folha. Traduzido por Gilda de Aquino. São Paulo: Brinque-Book, 2008.

KRESS, G. Meaning as resource: "naming" in a multimodal social-semiotic theory. In: KRESS, G. Multimodality: A social semiotic approach to contemporary communication. London and New York: Routledge, 2010. p. 103-131.

KRESS, G. Multimodality. In: COPE, B.; KALANTZIS, M. (Ed.). Multiliteracies: literary learning and the design of social futures. London: Routledge, 2000. p. 182-202.

KRESS, G.; VAN LEEUWEN, T. Reading Images: The Grammar of Visual Design. New York: Routledge, 1996.

LAJOLO, M. O que é literatura. 9. ed. São Paulo: Brasiliense, 1993.

MENDOZA FILLOLA, A. Literatura comparada e intertextualidad. Madrid: Editorial La Muralla, S.A., 1994.

PARANÁ. Secretaria de Estado da Educação. Diretrizes Curriculares da Educação Básica de Língua Portuguesa. Curitiba: SEED, 2008.

PROTETI, J. Árvore. São Paulo: Edições MMM, 2013.

REYES, Y. A casa imaginária: leitura e literatura na primeira infância. 1. ed. São Paulo: Global, 2010.

SILVEIRA, M. I. M. Modelos Teóricos e estratégias de leitura: suas implicações no Ensino. Maceió: EDUCAL, 2005.

SILVERSTEIN, S. A árvore generosa. Tradução de Fernando Sabino. 13. ed. São Paulo: Cosac Naify, 2012.

VARGAS LLOSA, M. La verdad de las mentiras. Barcelona: Seix Barral, 1996; Buenos Aires: Alfaguara. 2000.

VIGOTSKI, L. S. Psicologia e Pedagogia II: investigações experimentais sobre problemas didáticos específicos. v. 2. Lisboa: Biblioteca de Ciências Pedagógicas - Ed. Estampa, 1977.

ZILBERMAN, R. A escola e a leitura da literatura. In: ZILBERMAN, R.; RÖSING, T. M. K. Escola e leitura: velha crise, novas alternativas. São Paulo: Global, 2009.

ZUCKI, R. Letramento literário: práticas de leitura do texto literário nos anos iniciais do Ensino Fundamental. Dissertação (Mestrado Profissional) - Universidade Estadual do Oeste do Paraná, Cascavel, 2015. 